\title{
Information Characteristics on Instagram and Viewer Behavior
}

\author{
Eunmi Kim (D), Jae Eun (Francesca) Park (D), Jin-Young Kim (D), \\ and Chulmo $\mathrm{Koo}^{(\bowtie)}$ (iD \\ Smart Tourism Education Platform, Kyung Hee University, Seoul, South Korea \\ \{keunmi100, francesca. jep, jk293, helmetgu\}@khu.ac.kr
}

\begin{abstract}
Image-based social media such as Instagram is actively used as a tourism marketing channel that provides information regarding tourist destinations. Recognizing the importance of viewers' responses, this study investigated the relationship between viewers' responsive behavior and the characteristics of texts and images posted on Instagram. The results of multiple regression analysis showed that certain emotional expressions in hashtags and images that include people are positively associated with the number of likes and comments. This study provides insights into social media utilization strategies and post-marketing strategies that are helpful for DMO (Destination Marketing Organization).
\end{abstract}

Keywords: Customer behavior - Information characteristics - Social media • Instagram · DMO

\section{Introduction}

The growth and importance of smart tourism has been facilitated by the development of social media [1]. Social media is often used as a marketing tool that provides information and formulates a positive attitude about destinations [2]. As the visual image is a powerful tool that leads tourists' behavior [3], Instagram, which allows users to upload and share images with short texts and captions, has emerged as an actively used platform [4] in tourism. The texts and images in the post in turn affect viewers' responsive behavior. Despite the increasing importance of social media and Instagram, to the best of our knowledge few studies have explored the characteristics of texts and images, which elicit viewers' responsive behavior [5].

Prior studies mainly explored the marketing effect of the text reviews or the images. Investigating both texts and images simultaneously, this study aims to explore how the characteristics of visual and verbal information are related to viewers' responsive behaviors, using the Korea Tourism Organization (KTO)'s English Instagram account. Academically, this study expands the scope of understanding social media posts by adopting dual-coding theory [6]. This study also provides additional insights into social media marketing strategy and post-appeal-evaluation guidelines that are helpful in marketing.

This work was supported by the Ministry of Education of the Republic of Korea and the National Research Foundation of Korea (NRF-2019S1A3A2098438) 


\section{Literature Review}

Consumers' decision-making on experience goods and services such as tourism is greatly influenced by online contents on social media [7]. Social media users exchange and share useful information through texts and images [8]. Specifically, Instagram, which is an image-oriented platform [9], allows users to search for images more easily through hashtags. Hashtags also facilitate users to recommend specific posts to others with common interests [9]. Dual-coding theory postulates that visual and verbal information are processed differently [6]. Thus, this study identifies characteristics of Instagram information by texts (emotional expressions in the posts and the number of hashtags) and images (whether the image contains people or not).

Viewer behavior in social media has been categorized into consuming, contributing, and creating [10]. Through content-consumer interactions on Instagram, viewers receive sensory stimulation and in response they may engage in contributing reactions to the post; commenting or clicking on likes, for example. Prior studies examined the antecedents of reactive behavior on social media. Casalo et al. [11] found that consumers' interaction intentions positively affect the number of likes and comments. This study examines how consumers' reactive behavior, measured by the number of likes and comments on Instagram posts, varies according to the characteristics of texts, tags, and images of the posts that provide tourism information.

\section{Research Model and Hypothetical Development}

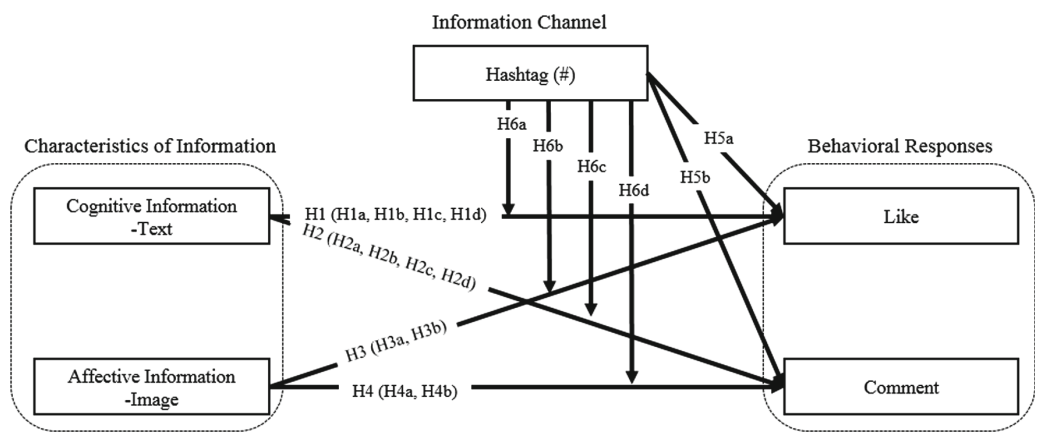

Fig. 1. Research framework

Figure 1 presents the research framework. Using dual-coding theory [6], information on Instagram was examined by two types-cognitive (texts) and affective (images). It has been reported that emotional expressions on social media posts affect viewers' behavioral reactions [12]. Thus, we examined the intensity of four emotions, namely, anticipation, joy, surprise, and trust from the text information. Since the account is operated by the national tourism organization, only positive emotions were considered. The characteristics of the text are expected to be associated with viewers' behavioral 
responses measured by the number of likes and comments. Thus, we propose the following hypotheses:

H1-H2: Characteristics of cognitive information (Text) is positively associated with the number of Likes/Comments.

H1a H1d/H2a H2d: The number of anticipation-, joy-, surprise-, and trustrelated words are positively associated with the number of Likes/Comments.

As for the images in the tourism context, the feeling of presence is likely to affect the behavioral intention. Photos with people were found to make viewers feel more present in the featured location [13]. Thus, in this current research, images were categorized by whether the photos contain people or not (images only contain scenery or objects without people). Thus, we hypothesize as follows:

H3-H4: Characteristics of affective information (Image) is positively associated with the number of Likes/Comments.

$\mathrm{H} 3 \mathrm{a}-\mathrm{H} 3 \mathrm{~b} / \mathrm{H} 4 \mathrm{a}-\mathrm{H} 4 \mathrm{~b}$ : Images with/without people are positively associated with the number of Likes/Comments.

With hashtags, people can search and collect posts more easily. So, the more hashtags, the higher potential to bring users, which result in a higher likelihood of active reactions. These premises can be hypothesized as:

H5a-H5b: The number of hashtags is positively associated with the number of Likes/Comments.

Further, when hashtags used with text and image can call more active responses. Appropriate hashtags will reinforce contents to reach additional users and thereby invite more likes and comments [14]. Therefore, we hypothesize as below:

H6a H6d: Hashtags moderate the relationship between the characteristics of cognitivelaffective information and the number of Likes/Comments.

\section{Research Methodology}

\subsection{Data}

Data were obtained from KTO's English Instagram account, which contains more than 800 posts with 310,000 followers as of August 2020. We collected likes, comments, and hashtags from 753 posts posted from 1st November 2017 through 31st July 2020. Table 1 shows the description of data. Images were categorized into 2 groups: photos with people and without people based on elements included in Chrome Developer tool. 
Table 1. Description of data

\begin{tabular}{|c|c|c|c|c|c|c|}
\hline Variables & Description & Obs. & Avg. & Std. & $\min$ & $\max$ \\
\hline Text & $\begin{array}{l}\text { Number of } \\
\text { emotional words } \\
\text { in the caption }\end{array}$ & 3,016 & 4.01 & 3.49 & 0 & 23 \\
\hline \multirow[t]{3}{*}{ Image } & $\begin{array}{l}\text { Photos without } \\
\text { people }=0\end{array}$ & $\begin{array}{l}489 \\
(64.9 \%)\end{array}$ & \multirow[t]{3}{*}{0.35} & \multirow[t]{3}{*}{0.48} & \multirow[t]{3}{*}{0} & \multirow[t]{3}{*}{1} \\
\hline & $\begin{array}{l}\text { Photos with } \\
\text { people = } 1\end{array}$ & $\begin{array}{l}264 \\
(35.1 \%)\end{array}$ & & & & \\
\hline & Total & $\begin{array}{l}753 \\
(100 \%)\end{array}$ & & & & \\
\hline Hashtag & $\begin{array}{l}\text { Number of } \\
\text { hashtags }\end{array}$ & 4,927 & 6.54 & 1.11 & 1 & 12 \\
\hline Like & Number of likes & $9,312,964$ & $12,367.46$ & $18,226.40$ & 682 & 221,169 \\
\hline Comment & $\begin{array}{l}\text { Number of } \\
\text { comments }\end{array}$ & 46,894 & 62.28 & 70.29 & 3 & 965 \\
\hline
\end{tabular}

\subsection{Methodology}

Multiple regression analysis was used to verify the hypothesized relationships. The number of likes and comments were converted to the log scale. For the text characteristics, the number of words related to positive emotions (Anticipation, Joy, Surprise, and Trust) was identified by sentiment analysis using the NRC (National Research Council Canada) emotion lexicon. We estimate the following equation:

Viewer response $=\beta_{0}+\beta_{1}$ Text_Char $+\beta_{2}$ Image_Char $+\beta_{3}$ Hashtag $+\beta_{4}$ Text Char $\times$ Hashtag $+\beta_{5}$ Image_Char $\times$ Hashtag $+\varepsilon$, where Viewer Response is Like and Comment; Text_Char is a vector of Anticipation, Joy, Surprise, and Trust; Image_Char is a dummy variable of Image; and $\varepsilon$ is an error term. All the explanatory variables were mean-centered. VIF (variance inflation factor) confirmed no issue of multicollinearity.

\subsection{Results}

Table 2 shows the results of analysis. Interestingly, emotional expressions in texts were not associated with Like (H1a-H1d), while Anticipation and Joy (H2a and H2b) were significant for Comment. Image and Hashtag indicated a significant relationship with Like and Comment (H3, H4, H6a, and H6b). As to $\mathrm{H} 3$ and $\mathrm{H} 4$, photo without people gathered more Like and Comment. While there was no moderating effect of Hashtag on the relationship between text characteristics and behavioral reactions ( $\mathrm{H} 5 \mathrm{a}$ and $\mathrm{H} 5 \mathrm{~b}$ ), negative moderating effects were found on the relationship between Image and behavioral reactions (Like and Comment) (H5c and $\mathrm{H} 5 \mathrm{~d})$. 
Table 2. Results of analysis

\begin{tabular}{|c|c|c|c|c|c|c|c|}
\hline \multicolumn{4}{|c|}{ Dependent variable: Like } & \multicolumn{4}{|c|}{ Dependent variable: Comment } \\
\hline & Coefficient & $\begin{array}{l}\text { Std. } \\
\text { error }\end{array}$ & t-value & & Coefficient & $\begin{array}{l}\text { Std. } \\
\text { error }\end{array}$ & t-value \\
\hline $\begin{array}{l}\text { Text_Char } \\
\text { Anticipation (H1a) } \\
\text { Joy (H1b) } \\
\text { Trust (H1c) } \\
\text { Surprise (H1d) }\end{array}$ & $\begin{array}{l}-0.024 \\
0.025 \\
0.015 \\
-0.028\end{array}$ & $\begin{array}{l}0.017 \\
0.016 \\
0.022 \\
0.019\end{array}$ & $\begin{array}{l}-1.432 \\
1.504 \\
0.664 \\
-1.449\end{array}$ & $\begin{array}{l}\text { Text_Char } \\
\text { Anticipation (H2a) } \\
\text { Joy (H2b) } \\
\text { Trust (H2c) } \\
\text { Surprise (H2d) }\end{array}$ & $\begin{array}{l}-0.030 \\
0.027 \\
0.022 \\
-0.013\end{array}$ & $\begin{array}{l}0.014 \\
0.014 \\
0.019 \\
0.016\end{array}$ & $\begin{array}{l}-2.122^{* * *} \\
1.980^{* * *} \\
1.195 \\
-0.793\end{array}$ \\
\hline Image $(\mathrm{H} 3)$ & 0.118 & 0.031 & $3.791^{* * * *}$ & Image (H4) & 0.068 & 0.026 & $2.598^{* * * *}$ \\
\hline $\begin{array}{l}\text { Hashtag } \times \text { Image } \\
(\mathrm{H} 5 \mathrm{c})\end{array}$ & -0.112 & 0.030 & $-3.721^{* * * *}$ & $\begin{array}{l}\text { Hashtag } \times \text { Image } \\
(\mathrm{H} 5 \mathrm{~d})\end{array}$ & -0.130 & 0.025 & $-5.205^{* * * *}$ \\
\hline Hashtag (H6a) & 0.111 & 0.014 & $8.174^{* * * *}$ & Hashtag (H6b) & 0.092 & 0.011 & $8.028^{* * *}$ \\
\hline
\end{tabular}

$* * *, * *$, and $*$ denote statistical significance at the $1 \%, 5 \%$, and $10 \%$ level, respectively.

\section{Conclusion}

This study examined the relationship between the information characteristics and viewers' behavioral responses considering visual (cognitive) and text (affective) information. The emotional expressions in Text were not associated with Like. While neither Trust nor Surprise are associated with Like and Comment, Anticipation and Joy were positively associated with Comment. As to Image, photos without people indicated stronger association with viewer responses. Concerning Hashtag, negative moderating effect was found on the relationship between Image and responsive behavior. Too many hashtags may drive the users to be confused. Future research may validate this point utilizing Geotags as well. This study expands the scope of understanding of the viewers' behavior on social media using Instagram. We provide useful and strategic social media management guidelines for both destination marketers and uploaders.

\section{References}

1. Gretzel U, Sigala M, Xiang Z, Koo C (2015) Smart tourism: foundations and developments. Electron Market 25(3):179-188

2. Hanan H, Putit N (2013) Express marketing of tourism destinations using Instagram in social media networking. In: Hospitality and tourism: synergizing creativity and innovation in research, p 471

3. Jenkins OH (2003) Photography and travel brochures: the circle of representation. Tour Geograph 5(3):305-328

4. Zappavigna M (2016) Social media photography: construing subjectivity in Instagram images. Vis Commun 15(3):271-292

5. Chan NL, Guillet BD (2011) Investigation of social media marketing: how does the hotel industry in Hong Kong perform in marketing on social media websites? J Travel Tour Market 28(4):345-368 
6. Paivio A (1991) Dual coding theory: retrospect and current status. Can J Psychol/Revue canadienne de psychologie 45(3):255

7. Hlee S, Lee H, Koo C, Chung N (2020) Will the relevance of review language and destination attractions be helpful? A data-driven approach. J Vacat Market 1-21

8. Parra-López E, Bulchand-Gidumal J, Gutiérrez-Taño D, Díaz-Armas R (2011) Intentions to use social media in organizing and taking vacation trips. Comput Hum Behav 27(2):640-654

9. Sheldon P, Bryant K (2016) Instagram: motives for its use and relationship to narcissism and contextual age. Comput Hum Behav 58:89-97

10. Muntinga DG, Moorman M, Smit EG (2011) Introduction COBRAs: exploring motivations for brand-related social media use. Int J Advert 30(1):13-46

11. Casaló LV, Flavián C, Ibáñez-Sánchez S (2017) Understanding consumer interaction on Instagram: the role of satisfaction, hedonism, and content characteristics. Cyberpsychol Behav Soc Network 20(6):369-375

12. Swani K, Milne G, Brown BP (2013) Spreading the word through likes on Facebook. J Res Interact Market 7(4):269-294

13. Jeong M, Choi J (2005) Effects of picture presentations on customers' behavioral intentions on the web. J Travel Tour Market 17(2-3):193-204

14. Giannoulakis S, Tsapatsoulis N (2016) Evaluating the descriptive power of Instagram hashtags. J Innov Digital Ecosyst 3(2):114-129

Open Access This chapter is licensed under the terms of the Creative Commons Attribution 4.0 International License (http://creativecommons.org/licenses/by/4.0/), which permits use, sharing, adaptation, distribution and reproduction in any medium or format, as long as you give appropriate credit to the original author(s) and the source, provide a link to the Creative Commons license and indicate if changes were made.

The images or other third party material in this chapter are included in the chapter's Creative Commons license, unless indicated otherwise in a credit line to the material. If material is not included in the chapter's Creative Commons license and your intended use is not permitted by statutory regulation or exceeds the permitted use, you will need to obtain permission directly from the copyright holder.

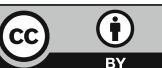

